\title{
Gene expression profiling of cancer stem cells in the Du145 prostate cancer cell line
}

\author{
WEI CHEN and GUO-MIN WANG \\ Department of Urology, Zhongshan Hospital of Fudan University, Shanghai 200032, P.R. China
}

Received October 25, 2011; Accepted December 28, 2011

DOI: 10.3892/ol.2012.565

\begin{abstract}
Cancer stem cells (CSCs) that exhibit tumorinitiating properties have been identified in primary prostate cancer and prostate cancer cell lines. CSCs are the root of tumor metastasis and recurrence even in the cases where they constitute a minority of the tumor mass. In this study, putative CSCs were isolated from the Du145 cell line and an Affymetrix microarray was used to investigate their gene expression profile. The results were validated by real-time polymerase chain reaction (PCR). The results of the microarray indicated that 138 genes were upregulated and 93 genes were downregulated in the CSCs. Certain genes that may be significant in the regulation of CSCs from the Du145 cell line were identified. These results may aid the studying of the mechanisms through which CSCs acquire their distinctive properties.
\end{abstract}

\section{Introduction}

Cancer stem cells (CSCs) are found in small populations in tumors. They have the properties of self-renewal, extensive differentiation and unlimited proliferation (1-3). The survival of CSCs was thought to be the ultimate cause of the metastasis and recurrence of a tumor (4). Prostatic CSCs have been identified in primary tumors and prostate-metastasized cancer (5).

We previously isolated and identified CSCs from the androgen-independent prostate carcinoma Du145 cell line (6). The CSCs express CD44, integrina2 $\beta 1$ and CD133. The cells have distinctive signal transfer pathways and gene expression patterns that are different from the rest of the cell population. Tsai (7) found that certain pathways associated with somatic stem cells, including wnt, notch and $\beta$-catenin, are also found in CSCs. Previously, we showed that a number of genes that are associated with the differentiation of somatic stem cells and cell apoptosis, including $\beta$-catenin, bax and myc, are differentially expressed in CSCs (6). However, the different levels of

Correspondence to: Dr Wei Chen and Dr Guo-Min Wang, Department of Urology, Zhongshan Hospital, No. 180 Fenglin Road, Shanghai 200032, P.R. China

E-mail: chen.wei3@zs-hospital.sh.cn; wang.guomin@zs-hospital.sh.cn

Key words: prostate cancer, cancer stem cells, microarray, gene expression profile expression of certain genes do not explain the mechanism of the unique nature of CSCs. To elucidate this mechanism, it is necessary to screen all the differentially expressed genes and describe the gene regulatory network in CSCs. Therefore, an oligonucleotide microarray was used to profile gene expression in $\mathrm{CD} 44^{+}$integrin $\alpha 2 \beta 1^{+} \mathrm{C} 133{ }^{+} \mathrm{CSC}$ and the unsorted cells from the Du145 cell line.

\section{Materials and methods}

MACS cell sorting for $C D 44^{+}$integrina $2 \beta 1^{+} \mathrm{CD} 133^{+}$cells. An anti-PE MultiSort kit (anti-PE MACS microbeads, microbead release reagent) and a MACS separator (Miltenyi Biotech Ltd.) were used to indirectly isolate CD $44^{+}$cells. As reported previously (6), cells were labeled with anti-CD44-PE (eBioscience) for $5 \mathrm{~min}$ and then incubated with MACS goat anti-PE IgG microbeads for $15 \mathrm{~min}$ at $4^{\circ} \mathrm{C}$. The cell suspension was rinsed with PBS containing $0.5 \%$ bovine serum albumin and 2 mM EDTA (PBE), centrifuged, resuspended in 1,000 $\mu 1 \mathrm{PBE}$ and applied to a MACS column. Labeled CD44+ ${ }^{+}$basal cells were eluted and resuspended in $1 \mathrm{ml}$ PBE. Release reagent (20 $\mu 1$ ) was added to the cell suspension, which was then incubated for $10 \mathrm{~min}$ at $4^{\circ} \mathrm{C}$. The reaction was stopped with $30 \mu 1$ MultiSort stop reagent per $10^{7}$ cells. The cells passed through a MACS column, with the free microbeads removed from the cells. CD $44^{+}$basal cells were plated onto dishes coated with type I collagen $(100 \mu \mathrm{g} / \mathrm{ml})$ for $5 \mathrm{~min}$. Following this time interval, the adherent cells were found to be CD $44^{+}$integrin $\alpha 2 \beta 1^{+}$cells. The cells were then rinsed with PBS and harvested with Accutase ${ }^{\mathrm{TM}}$ (Chemicon International, Inc., Temecula, CA, USA). As we have previously reported (6), the CD $44^{+}$integrin $\alpha 2 \beta 1^{+}$cells were applied to the direct MACS cell sorting for $\mathrm{CD} 133^{+}$cells.

Flow cytometric analysis. Aliquots of sorted cells were suspended in PBE in a volume of $100 \mu \mathrm{l}$ for antibody labeling. Anti-CD133-FITC (10 $\mu \mathrm{l})$ and 1:200 anti-CD44 antibody-PE (Novus Biologicals, LLC, Littleton, CO, USA) monoclonal antibodies were added to the cell suspension. The reaction was incubated in the dark for $10 \mathrm{~min}$ at $4^{\circ} \mathrm{C}$. The cells were washed and centrifuged in triplicate and resuspended in $500 \mu \mathrm{l} \mathrm{PBE}$. Flow analysis was performed with a FACScan (FACSCalibur, Becton-Dickinson) with a 488-nm laser. A control with no antibody was analyzed to delineate the unstained and autofluorescent population, with the percentage of positive events determined. 

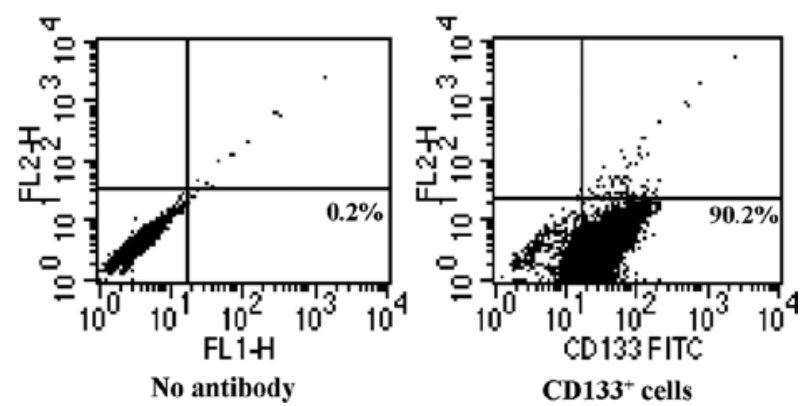

Figure 1. Results of flow cytometric analysis revealed that the purity of the $\mathrm{CD}_{133}{ }^{+}$cells was $90.2 \%$.

Isolation of total RNA. An RNeasy Mini kit (Qiagen, Hilden, Germany) was used to extract total RNA from the cell samples according to the manufacturer's instructions. The RNA in the aqueous phase was moved to a fresh RNA-free tube and mixed with 1/10 volume of $3 \mathrm{M} \mathrm{NaOAc}$ (Sigma-Aldrich, St. Louis, MO, USA) and 2.5 volumes of ethanol. The samples were incubated at $-20^{\circ} \mathrm{C}$ for at least $1 \mathrm{~h}$ and centrifuged at $12,000 \mathrm{x} \mathrm{g}$ for $20 \mathrm{~min}$ at $4^{\circ} \mathrm{C}$. The supernatant was removed and the RNA pellet was washed twice with $80 \%$ ethanol, redissolved in diethylpyrocarbonate-treated water and stored at $-80^{\circ} \mathrm{C}$. The quality of the RNA was analyzed using a UV spectrophotometer (Affymetrix, Santa Clara, CA, USA). To determine the concentration and purity of the samples, the absorbance was checked at 260 and $280 \mathrm{~nm}$. The 260:280 ratio of the RNA was 1.8:2.0.

Affymetrix microarray for gene expression. Affymetrix microarrays (Affymetrix U 133 plus 2.0, Affymetrix) were used to analyze the transcriptional profiles of the RNA samples. There were 54,000 probes on each slide. Biotin-labeled cRNA was generated and linearly amplified from total RNA using the MEGAscript ${ }^{\circledR}$ T7 kit (Ambion, Inc., USA) according to the manufacturer's instructions.

Array hybridization, chemiluminescence detection and image acquisition and analysis were performed using a chemiluminescence detection kit (Affymetrix) and a chemiluminescence scanner (Affymetrix ${ }^{\circledR}$ GeneChip ${ }^{\circledR}$ Scanner 3000 , Affymetrix) according to the manufacturer's instructions. The experiments were performed in triplicate. Each microarray was first prehybridized at $45^{\circ} \mathrm{C}$ for $10 \mathrm{~min}$ in a hybridization buffer with a blocking reagent. Labeled cRNA targets were first fragmented by incubation with a fragmentation buffer at $94^{\circ} \mathrm{C}$ for $35 \mathrm{~min}$ and hybridized to each prehybridized microarray in a volume of $250 \mu \mathrm{g}$ at $45^{\circ} \mathrm{C}$ for $16 \mathrm{~h}$. Following hybridization, the arrays were washed with a hybridization wash buffer and a chemiluminescence rinse buffer. Chemiluminescent signals were generated by first incubating the arrays with biotinylated antibody (anti-streptavidin antibody, Vector Laboratories, Burlingame, CA, USA) and adding chemiluminescenceenhancing solution and chemiluminescence substrate. Images were captured for each microarray using the chemiluminescence scanner and GCOS software (Affymetrix).

Data analysis. The GCOS software was used to extract assay signals and assay signal-to-noise ratios from the microarray

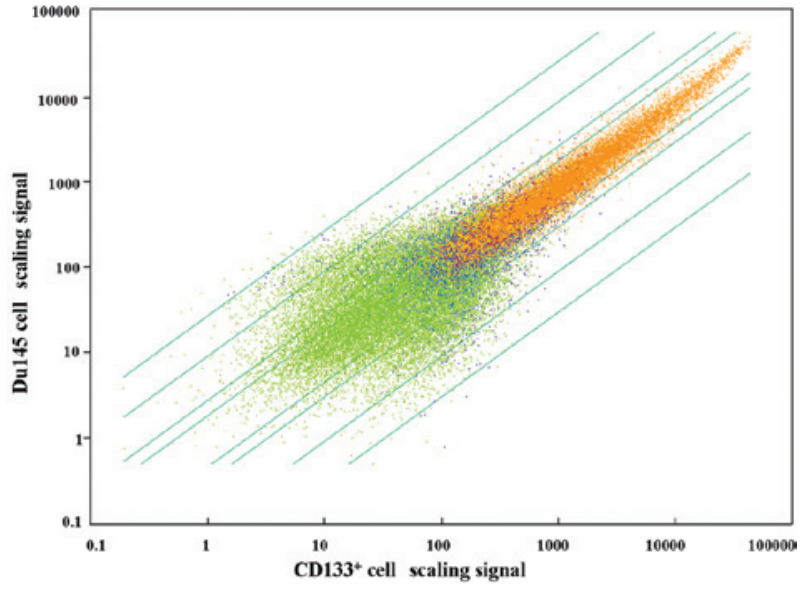

Figure 2. Gene expression scaling signal scatters in the unsorted cells and $\mathrm{CD} 44^{+}$integrin $\alpha 2 \beta 1^{+} \mathrm{C} 133^{+}$cells from the Du145 cell line. Orange, gene expression signal detected in the two cell groups; blue, gene expression signal detected only in one of the cell groups; green, gene expression signal detected in neither of the cell groups.

images. The chemiluminescence intensity for each spot was calculated using local mean background subtraction. Normalization was performed as a two-step process, first using the internal standards present on the array (different genes allowing quantification/normalization and estimation of experimental variation) and second using a set of housekeeping genes. The variance of the normalized set of housekeeping genes was used to generate a confidence interval to test the significance of the gene expression ratios obtained (sorted cells versus control). Ratios outside the $95 \%$ confidence interval were considered to indicate statistically significant results. The ratios of assay signals of the genes were log-transformed and represented graphically using Microsoft Excel. Standard deviations were not calculated due to the use of a log scale. The genes with an expression ratio change $>2$-fold were selected and classified according to their functions (cell cycle, cell proliferation and cell apoptosis) with GCOS 1.2.

Real-time polymerase chain reaction (PCR). Real-time PCR was performed using the method we reported previously (6). RNA was extracted using TRIzol reagent (Invitrogen Life Technologies, Carlsbad, CA, USA). RNA was quantified using UV spectrophotometry and was used to create cDNA with the SuperScript RT-PCR kit (Invitrogen Life Technologies). The PCR co-amplification of the genes was carried out with $\beta$-actin in the iCycler iQTM real-time PCR detection system (Bio-Rad, Richmond, CA, USA) using the reaction mixture in a total volume of $25 \mu$ l containing $12.5 \mu 1$ SYBR-Green real-time PCR mix (Toyobo, Osaka, Japan), $11 \mu 1 \mathrm{ddH}_{2} \mathrm{O}, 0.5 \mu \mathrm{l}(1 \mu \mathrm{M})$ sense and antisense primers and $0.5 \mu \mathrm{l}$ cDNA. Real-time PCR was performed in triplicate. A reaction mixture containing $\beta$-actin primers but omitting cDNA was used as the negative control. The primers of bax, fas, c-myc, survivin, $\beta$-catenin and $\beta$-actin and the detailed methods used were as previously reported (6). At the end of each cycle, the fluorescence emitted by SYBRGreen was measured. The expression level of the target gene in $\mathrm{CD} 44^{+}$integrin $\alpha 2 \beta 1^{+} \mathrm{C} 133^{+}$cells relative to that in unsorted cells was calculated using the formula: fold change $=2^{-\Delta \Delta \mathrm{Ct}}$, where 
Table I. Overexpressed genes in cancer stem cells.

\begin{tabular}{|c|c|c|c|}
\hline $\begin{array}{l}\text { Signal log } \\
\text { ratio }\end{array}$ & $\begin{array}{c}\text { Representative } \\
\text { public ID }\end{array}$ & Gene title & $\begin{array}{c}\text { Gene } \\
\text { symbol }\end{array}$ \\
\hline \multicolumn{4}{|l|}{ Apoptosis } \\
\hline 2.4 & NM_000399 & Early growth response 2 (Krox-20 homolog, Drosophila) & EGR2 \\
\hline 1.7 & M57731 & Chemokine (C-X-C motif) ligand 2 & CXCL2 \\
\hline 1.5 & NM_000948 & Prolactin & PRL \\
\hline 1.3 & AA005141 & Met proto-oncogene (hepatocyte growth factor receptor) & MET \\
\hline 1.3 & AF130085 & Catenin (cadherin-associated protein), $\beta 1,88 \mathrm{kDa}$ & CTNNB1 \\
\hline 1.1 & NM_001511 & Chemokine (C-X-C motif) ligand 1 (melanoma growth-stimulating activity, $\alpha$ ) & CXCL1 \\
\hline 1 & NM_002006 & Fibroblast growth factor 2 (basic) & FGF2 \\
\hline 1 & NM_000620 & Nitric oxide synthase 1 (neuronal) & NOS1 \\
\hline \multicolumn{4}{|c|}{ Cell binding } \\
\hline 4.8 & BF977837 & KIAA0527 protein & KIAA0527 \\
\hline 4.6 & NM_007136 & Zinc finger protein 80 (pT17) & ZNF80 \\
\hline 4.3 & ВC007908 & TBC1 domain family, member 10 & TBC1D10 \\
\hline 4.1 & AU148255 & Eukaryotic translation initiation factor 4E-binding protein 3 & ANKHD1 \\
\hline 3.5 & NM_006186 & Nuclear receptor subfamily 4 , group A, member 2 & NR4A2 \\
\hline 3 & S77154 & Nuclear receptor subfamily 4 , group A, member 2 & NR4A2 \\
\hline 2.5 & NM_002702 & POU domain, class 6 , transcription factor 1 & POU6F1 \\
\hline 2 & NM_001674 & Activating transcription factor 3 & ATF3 \\
\hline \multicolumn{4}{|l|}{ Signaling } \\
\hline 3.5 & NM_006186 & Nuclear receptor subfamily 4 , group A, member 2 & NR4A2 \\
\hline 3 & S77154 & Nuclear receptor subfamily 4 , group A, member 2 & NR4A2 \\
\hline 2.1 & AA295257 & Neuropilin 2 & NRP2 \\
\hline 1.8 & AV700298 & CD44 antigen (homing function and Indian blood group system) & CD44 \\
\hline 1.2 & J05008 & Endothelin 1 & EDN1 \\
\hline 1.1 & NM_001511 & Chemokine (C-X-C motif) ligand 1 (melanoma growth stimulating activity, alpha) & CXCL1 \\
\hline 1 & NM_000584 & Interleukin 8 & IL8 \\
\hline 1 & NM_003877 & Suppressor of cytokine signaling 2 & SOCS2 \\
\hline \multicolumn{4}{|c|}{ Degeneration } \\
\hline 1.4 & AI468201 & Thrombospondin 3 & THBS3 \\
\hline 1.3 & AF130085 & Catenin (cadherin-associated protein), $\beta 1,88 \mathrm{kDa}$ & CTNNB1 \\
\hline 1 & AA156873 & Integrin, $\alpha 1$ & PELO \\
\hline 1 & AL039870 & Guanine nucleotide-binding protein (G protein), $\gamma 7$ & GNG7 \\
\hline \multicolumn{4}{|c|}{ Metabolism } \\
\hline 2.5 & U20489 & NADH dehydrogenase 5 & MTND5 \\
\hline 2.2 & AI651445 & Hypothetical protein MGC4655 & MGC4655 \\
\hline 2.1 & AA295257 & Neuropilin 2 & NRP2 \\
\hline 1.9 & ВC003143 & Dual specificity phosphatase 6 & DUSP6 \\
\hline 1.9 & AK025352 & Microtubule-associated serine/threonine kinase 2 & MAST2 \\
\hline \multicolumn{4}{|l|}{ Cell cycle } \\
\hline 3 & NM_006732 & FBJ murine osteosarcoma viral oncogene homolog B & FOSB \\
\hline 1.9 & AA994334 & B-cell CLL/lymphoma 10 & BCL10 \\
\hline 1.9 & ВC003143 & Dual specificity phosphatase 6 & DUSP6 \\
\hline 1.8 & AK025101 & Exostoses (multiple) 1 & EXT1 \\
\hline 1.8 & ВC003143 & Dual specificity phosphatase 6 & DUSP6 \\
\hline
\end{tabular}

$\Delta \Delta \mathrm{Ct}=[\mathrm{Ct}($ target gene $)-\mathrm{Ct}(\beta$-actin $)] \mathrm{CD} 44^{+}$integrin $\alpha 2 \beta 1^{+} \mathrm{C} 133^{+}$ cells - $[\mathrm{Ct}$ (target gene)- $\mathrm{Ct}(\beta$-actin $)]$ unsorted cells.

\section{Results}

Highly purified CSCs were sorted from Dul45 cells. We obtained the CSCs using the multitarget MACS cell sorter. The purity of the $\mathrm{CD} 133^{+}$cells was $90.2 \%$ (Fig. 1).
Identification of genes differentially expressed in CSCs and Du145 cells. Using the Student's t-test examination and fold change methods (signal log ratio $\geq 1$ or $\leq-1$ ), 454 transcripts and variants were found to be differentially expressed, including 231 genes whose titles and functions were determined. Of these, 138 genes were upregulated and 93 were downregulated in the CSCs. The signal scatters of the two groups of cells are shown in Fig. 2. 
Table II. Underexpressed genes in cancer stem cells.

\begin{tabular}{|c|c|c|c|}
\hline $\begin{array}{l}\text { Signal log } \\
\text { ratio }\end{array}$ & $\begin{array}{l}\text { Representative } \\
\text { public ID }\end{array}$ & Gene title & $\begin{array}{c}\text { Gene } \\
\text { symbol }\end{array}$ \\
\hline \multicolumn{4}{|l|}{ Apoptosis } \\
\hline-3.4 & L22454 & Nuclear respiratory factor 1 & NRF1 \\
\hline-1.4 & AI880383 & Natural killer-tumor recognition sequence & NKTR \\
\hline-1.1 & BG612458 & Heat shock $90 \mathrm{kDa}$ protein $1, \beta$ & HSPCB \\
\hline-1.1 & NM_001729 & Betacellulin & BTC \\
\hline-1 & NM_000978 & Ribosomal protein L23 & RPL23 \\
\hline-1 & NM_015965 & Cell death-regulatory protein GRIM19 & GRIM19 \\
\hline \multicolumn{4}{|c|}{ Cell binding } \\
\hline-1.3 & M74447 & Transporter 2, ATP-binding cassette, subfamily B & TAP2 \\
\hline-2 & & Zinc finger protein 555 & ZNF555 \\
\hline-1 & BG032366 & Interleukin enhancer-binding factor $3,90 \mathrm{kDa}$ & ILF3 \\
\hline-1 & ВС020837 & Zinc finger protein 505 & ZNF505 \\
\hline \multicolumn{4}{|c|}{ Transcription regulation } \\
\hline-3.4 & L22454 & Nuclear respiratory factor 1 & NRF1 \\
\hline-2.8 & AB055703 & LIM homeobox 4 & LHX4 \\
\hline-1.2 & NM_004862 & Lipopolysaccharide-induced TNF factor & LITAF \\
\hline-1 & U26455 & Ataxia telangiectasia mutated & ATM \\
\hline \multicolumn{4}{|l|}{ Signaling } \\
\hline-3.7 & AK027217 & LIM protein & LIM \\
\hline-1.7 & AW504458 & Guanine nucleotide-binding protein ( $\mathrm{G}$ protein), $\beta$ polypeptide 4 & GNB4 \\
\hline-1.3 & AF033111 & CD27-binding (Siva) protein & SIVA \\
\hline-1.3 & M74447 & Transporter 2, ATP-binding cassette, subfamily B & TAP2 \\
\hline-1.2 & NM_004862 & Lipopolysaccharide-induced TNF factor & LITAF \\
\hline-1.1 & NM_006579 & Emopamil-binding protein (sterol isomerase) & EBP \\
\hline-1.1 & NM_013437 & Low density lipoprotein-related protein 12 & LRP12 \\
\hline-1 & NM_000820 & Growth arrest-specific 6 & GAS6 \\
\hline \multicolumn{4}{|c|}{ Degeneration } \\
\hline-1.7 & AW504458 & Guanine nucleotide-binding protein ( $\mathrm{G}$ protein), $\beta$ polypeptide 4 & GNB4 \\
\hline-1.3 & BF063156 & RNA-binding motif protein 17 & RBM17 \\
\hline-1.2 & BE561798 & HLA class II region expressed gene KE2 & HKE2 \\
\hline-1 & AW675725 & Baculoviral IAP repeat-containing 4 & BIRC4 \\
\hline \multicolumn{4}{|c|}{ Metabolism } \\
\hline-4.2 & AF153430 & Cyclin-dependent kinase (CDC2-like) 10 & CDK10 \\
\hline-2 & AU156915 & Methylcrotonoyl-Coenzyme A carboxylase 2 ( $\beta$ ) & MCCC2 \\
\hline-1.8 & AI142677 & Glutamyl-prolyl-tRNA synthetase & EPRS \\
\hline-1.8 & NM_014502 & PRP19/PSO4 homolog (S. cerevisiae) & PRP19 \\
\hline-1.7 & AI809582 & E1A-binding protein $\mathrm{p} 400$ & EP400 \\
\hline-1.6 & D84430 & Phenylalanine-tRNA synthetase-like, $\beta$ subunit & FARSLB \\
\hline-1.5 & U18197 & ATP citrate lyase & ACLY \\
\hline-1.5 & BG252666 & ATPase, class I, type 8B, member 1 & ATP8B1 \\
\hline-1.5 & BF127479 & Ribonuclease H1 & RNASEH1 \\
\hline-1.4 & AI880383 & Natural killer-tumor recognition sequence & NKTR \\
\hline-1.4 & S72422 & Dihydrolipoamide S-succinyltransferase & DLST \\
\hline-1.4 & AB037769 & Pyruvate dehydrogenase phosphatase isoenzyme 2 & PDP2 \\
\hline-1.3 & M74447 & Transporter 2, ATP-binding cassette, subfamily B & TAP2 \\
\hline-1.3 & AF281132 & Exosome component 3 & EXOSC3 \\
\hline-1.3 & AV706522 & Hypothetical protein DKFZp761G058 & DKFZp761G058 \\
\hline-1.2 & AA639797 & ATPase, class VI, type 11B & ATP11B \\
\hline-1.2 & C18318 & Ring finger and $\mathrm{KH}$ domain-containing 1 & RKHD1 \\
\hline \multicolumn{4}{|l|}{ Cell cycle } \\
\hline-4.2 & AF153430 & Cyclin-dependent kinase (CDC2-like) 10 & CDK10 \\
\hline-1 & NM_002312 & Ligase IV, DNA, ATP-dependent & LIG4 \\
\hline-1 & NM_003158 & Serine/threonine kinase 6 & STK6 \\
\hline-1.5 & AK024690 & Hypothetical protein LOC90110 & FBXL20 \\
\hline-1.5 & AA761259 & Rap guanine nucleotide exchange factor (GEF) 1 & RAPGEF1 \\
\hline
\end{tabular}




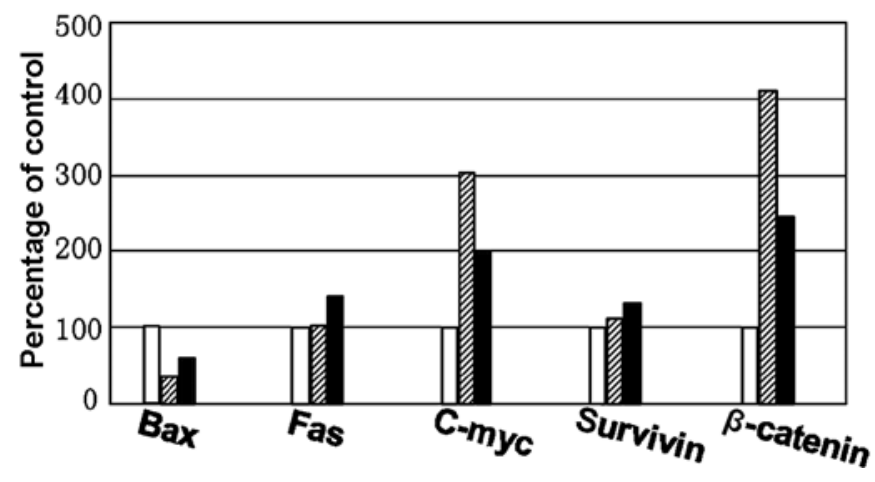

Figure 3. Results of the microarray compared with the results of real-time PCR. The results of the microarray were similar to those of real-time PCR. The gene expression level of the cells in the control group was set at $100 \%$. White bar, control; striped bar, the gene expression level detected with real-time PCR; black bar, the gene expression level detected with microarray.

Classification of significantly expressed genes. Hierarchical cluster analysis was used to classify the differentially expressed genes according to their function by means of GCOS 1.2 software. The roles of the genes included tumorigenesis, tumor suppression, apoptosis, tumor angiogenesis and cell cycle regulation. The results are shown in Tables I and II.

Validation of significantly expressed genes by real-time $P C R$. To validate the microarray results, we selected several genes which we previously detected using real-time PCR (6). Therefore, the expression of bax, fas, c-myc, survivin and $\beta$-catenin was examined.

$C$-myc and $\beta$-catenin in CSCs were detected to be overexpressed and bax underexpressed. The expression levels of fas and survivin had no significant difference between the CSCs and unsorted cells, similar to the microarray results. The magnitude of expression changes detected by real-time PCR was comparable with the fold changes detected by the microarray platform (Fig. 3).

\section{Discussion}

The proportion of CSCs in a tumor is very small. CSCs have distinctive biological properties; their signal transfer pathways and patterns of expression of certain genes are different from those of other types of cells, but similar to those of stem cells $(8,9)$. CSCs are able to survive in adverse environments and resist anticancer therapy through certain mechanisms $(10,11)$. For example, leukemia stem cells are capable of resisting apoptosis by regulating bcl-2 and bax (12).

Less is known concerning the molecular biological nature of prostate CSCs. In this study, an Affymetrix microarray was used to detect the genes which were expressed at significantly different levels in CSCs from the Du145 cell line.

We found that 44 genes associated with apoptosis, tumor proliferation and differentiation were overexpressed (including b-FGF, EGR2, CXCL1, PRL, MET, IL-24, NOS1, CXCL2 and $\beta$-catenin), 22 were downregulated (including RPL23, HSPCB and NKTR), 31 signal transducer-associated genes were upregulated (including SOCS2, EDN1 and CXCL1) and 10 were downregulated (including GNB4, SIVA and LITAF) in CSCs. In addition, the expression levels of genes that are involved in metabolism, transcription regulation, enzyme regulation and the cell cycle were also altered. The underexpression of LITAF (lipopolysaccharide-induced TNF factor) and NKTR (natural killer-tumor recognition sequence) may protect prostate CSCs from destruction by the immune system or immunotherapy. The different expression levels of genes involved in the regulation of transcription and enzyme activity may affect the migration and invasion of cancer cells.

Gene profiling microarray is very efficient. It provides an accurate timepoint analysis of a sample $(13,14)$, but its results are variable even in similar tissues or cells due to the changes in environment as well as the sample age. The treatment of samples (15) and the quality of the RNA and probes (16) also affect the microarray results. Therefore, the microarray results are thought to be difficult to repeat. In this study, in order to guarantee an identical environment, the generation and treatment of the samples were exactly the same. CSCs were immediately isolated from the Du145 cells prior to the extraction of total RNA. The standard Affymetrix microarray and processes were then used to examine the expression profile of the CSCs and unsorted cells. We compared the results of the microarray with that of real-time PCR. The results of the microarray were similar to those of the real-time PCR.

The CSCs acquire their distinctive properties through the regulation of a number of pathways and multiple genes. This study primarily selected the differentially expressed genes in CSCs from the Du145 cell line. It provides new insights into the study of the molecular biological nature of prostate CSCs.

\section{Acknowledgements}

This study was supported by the NSFC (Natural Science Foundation of China, no. 30901705) and the Doctoral Fund of Ministry of Education of China (no. 20090071120024). We thank Dr Wei Zhang, Dr Xiu-ling Zhi, Mr. Chen Xu, Ms. Yi-ping $\mathrm{Gu}$ and Linda for technical advice regarding the study.

\section{References}

1. Bonnet D and Dick JE: Human acute myeloid leukemia is organized as a hierarchy that originates from a primitive hematopoietic cell. Nat Med 3: 730-737, 1997.

2. Singh SK, Clarke ID, Terasaki M, Bonn VE, Hawkins C, Squire J and Dirks PB: Identification of a cancer stem cell in human brain tumors. Cancer Res 63: 5821-5828, 2003.

3. Singh SK, Hawkins C, Clarke ID, Squire JA, Bayani J, Hide T, Henkelman RM, Cusimano MD and Dirks PB: Identification of human brain tumour initiating cells. Nature 432: 396-401, 2004.

4. Al-Hajj M, Wicha MS, Benito-Hernandez A, Morrison SJ and Clarke MF: Prospective identification of tumorigenic breast cancer cells. Proc Natl Acad Sci USA 100: 3983-3988, 2003.

5. Collins AT, Berry PA, Hyde C, Stower MJ and Maitland NJ: Prospective identification of tumorigenic prostate cancer stem cells. Cancer Res 65: 10946-10951, 2005.

6. Wei C, Guomin W, Yujun L and Ruizhe Q: Cancer stem-like cells in human prostate carcinoma cells DU145: the seeds of the cell line? Cancer Biol Ther 6: 763-768, 2007.

7. Tsai RY: A molecular view of stem cell and cancer cell self-renewal. Int J Biochem Cell Biol 36: 684-694, 2004. 
8. Chiba T, Miyagi S, Saraya A, Aoki R, Seki A, Morita Y, Yonemitsu Y, Yokosuka O, Taniguchi $\mathrm{H}$, Nakauchi $\mathrm{H}$ and Iwama A: The polycomb gene product BMI1 contributes to the maintenance of tumor-initiating side population cells in hepatocellular carcinoma. Cancer Res 68: 7742-7749, 2008.

9. Bresson-Mazet C, Gandrillon O and Gonin-Giraud S: Stem cell antigen 2: a new gene involved in the self-renewal of erythroid progenitors. Cell Prolif 41: 726-738, 2008.

10. Zhou S, Schuetz JD, Bunting KD, Colapietro AM, Sampath J, Morris JJ, Lagutina I, Grosveld GC, Osawa M, Nakauchi H and Sorrentino BP: The ABC transporter Bcrp1/ABCG2 is expressed in a wide variety of stem cells and is a molecular determinant of the side-population phenotype. Nature Med 7: 1028-1034, 2001.

11. Raguz S and Yagüe E: Resistance to chemotherapy: new treatments and novel insights into an old problem. Br J Cancer 99: 387-391, 2008

12. Domen J, Gandy KL and Weissman IL: Systemic overexpression of bcl-2 in the hematopoietic system protects transgenic mice from the consequences of lethal irradiation. Blood 91: 2272-2282, 1998 .
13. Ermolaeva O, Rastogi M, Pruitt KD, Schuler GD, Bittner ML, Chen Y, Simon R, Meltzer P, Trent JM and Boguski MS: Data management and analysis for gene expression arrays. Nat Genet 20: $19-23,1998$.

14. Ramsay G: DNA chips: state-of-the-art. Nat Biotechnol 16 40-44, 1998.

15. Tanner MA, Berk LS, Felten DL, Blidy AD, Bit SL and Ruff DW: Substantial changes in gene expression level due to the storage temperature and storage duration of human whole blood. Clin Lab Haematol 24: 337-341, 2002.

16. Petalidis L, Bhattacharyya S, Morris GA, Collins VP, Freeman TC and Lyons PA: Global amplification of mRNA by template switching PCR: linearity and application to microarray analysis. Nucleic Acids Res 31: e142, 2003. 